\title{
O ENUNCIATÁRIO EM POESIAS DIGITAIS
}

\section{THE ENUNCIATEE ON THE DIGITAL POETRY}

REGINA SOUZA GOMES*

RESUMO: As mudanças produzidas pelas novas práticas de relações intersubjetivas na internet, envolvendo os textos poéticos publicados na web, merecem a atenção dos estudiosos do discurso. Neste artigo, analisaremos o estatuto de participação do enunciatário de poesias digitais de língua portuguesa, a partir do quadro teórico da semiótica de linha francesa, observando seus modos de presença e práticas de leitura, apreensíveis pelos próprios enunciados. Levaremos principalmente em conta poemas que utilizam os recursos sincréticos, com animação, que o meio digital disponibiliza, publicados em diversos sites de poesia e sites oficiais de poetas disponíveis na web (sites como Errática, Zunái, Cronópios etc., e os de autores como o de Arnaldo Antunes, o de Augusto de Campos, entre outros), verificando como constituem o ciberleitor. Identificamos, na variedade de modos de leitura e de participação do enunciatário, uma tipologia que organiza em traços gerais as formas de constituição desses leitores, relativamente à competencialização cognitiva e pragmática pressuposta à leitura e à maneira como fazem face à convoca-

\footnotetext{
* Docente da UFRJ - Universidade Federal do Rio de Janeiro. E-mail: reginagomes@letras.ufrj.br.
} 
ção pelo enunciador à participação e à experimentação lúdica e estética dos recursos expressivos. Enfim, é preciso compreender também de que modo essas práticas de leitura se aproximam ou se distanciam das que já se fazem presentes nos textos impressos.

PALAVRAS-CHAVE: Enunciatário. Poesia digital. Interação enunciativa. Participação. Leitura.

ABSTRACT: The changes produced by the new practices of intersubjective relationships on the Internet, involving the poetic texts published on the web, deserve the discourse researchers' attention. In this paper, we will analyze, from the theoretical framework of French Semiotics, the participation status of the digital poetry enunciatee in Portuguese language, by observing the presence modes and reading practices apprehensible on the enunciate. Mainly, we will take into account the poems available on the digital environment that make use of syncretic resources, more specifically, animation. We considered the ones published in several poetry sites and official poets' webpages (as Errática, Zunái, Cronópios, etc., and the Arnaldo Antunes's and Augusto de Campos's websites, among others), to understand how the cyber-reader profile is built. We have identified, in terms of modes of reading and enunciatee participation, a typology that organizes in general, the manner these readers are constituted, in relation to the cognitive and pragmatic ability, presumed to reading, and how the reader reacts to the enunciator's call to participate and to try the aesthetic and the ludic aspects of the expressive resources. Finally, it is also necessary to understand how these reading practices get closer or further away from those practices, which are already part of the printed texts. 
KEYWORDS: Enunciatee. Digital poetry. Enunciative interaction. Participation. Reading.

\section{Introdução}

O objetivo deste artigo é analisar a constituição do enunciatário de poesias digitais que utilizam recursos estéticos sincréticos, verbo-sonoro-visuais, com animação, em língua portuguesa, publicados na internet, considerando seus modos de participação e fruição estética, à luz da semiótica de linha francesa.

Os textos analisados formam um corpus representativo, composto a partir de poesias publicadas em sites de poesia ( $\mathrm{Er}$ rática, Zunái, Cronópios etc.), de sites oficiais de poetas (Arnaldo Antunes, Augusto de Campos, Agnus Valente e Nardo Germano etc.) e de seletas de poemas digitais reunidos em publicações de sites especializados como o Electronic Literature Collection $^{1}$. Desse conjunto de textos, utilizaremos alguns deles como exemplificação e comprovação dos fenômenos observados.

Para abordar o estatuto do enunciatário nesses poemas, é preciso considerar, primeiramente, que o modo de ler na internet exige certos saberes cognitivos (reconhecer os links, os hipertextos ou outras possibilidades dinâmicas da expressão inseridas nos textos, e o modo como acessá-los) e pragmáticos (clicar, arrastar, mover botões), já previstos na própria construção do enunciado poético digital. Além disso, é preciso compreender como característico do modo de ler

1 Electronic Literature Collection é uma publicação do site Electronic Literature Organization, que tem como finalidade "facilitar e promover a escrita, a publicação, e a leitura da literatura na mídia eletrônica”. A literatura eletrônica, originada e criada explicitamente no e para o computador, é um dos objetos de interesse do site. Disponível em: 〈http:// collection.eliterature.org/ >. Acesso em: 13 dez. 2015. 
na internet a dispersão e o envolvimento simultâneo do leitor em muitas tarefas (verificação de $e$-mails, participação em bate-papos, Facebook, além de variados pop-ups que irrompem na tela). 0 internauta, então, busca sempre a abertura e o desdobramento do texto em links, além de crer participar ativamente da própria produção dos enunciados, ao escolher trajetórias de leitura que se materializam em outras camadas de enunciados. Do ponto de vista passional, é um sujeito ansioso e inquieto. Aspectualmente, espera sempre que o texto dado a ler, geralmente decorrente de uma gestualidade própria, se antecipe. Todos esses elementos se fazem ver pelas marcas deixadas na produção poética, e acabam por influir nos modos de fruição estética e na forma mais ou menos concentrada e totalizante de leitura.

Desta forma, as poesias digitais fazem face a essa dispersão e aceleração por meio de estratégias para deter a atenção do leitor: ou obrigam a uma parada e uma concentração da atenção ou amplificam a participação somática. Em relação à primeira estratégia, há um desenrolar lento do texto audiovisual, sem possibilidade de interrupção. Não há, no enunciado, qualquer meio de interromper o desencadeamento do texto ou recomeçar de algum ponto específico escolhido pelo leitor, fazendo com que qualquer distração obrigue o recomeço iterativo do texto. Na segunda estratégia, o enunciador inclui no enunciado gatilhos que obriguem o leitor a clicar, arrastar, mover elementos para que a poesia chegue a seu termo, tenha continuidade ou se transforme. A ação do enunciatário possibilita que o poema se realize, se materialize e possa ser experimentado, envolvendo, assim, o leitor.

No entanto, como sabemos, na internet, nem sempre a poesia emprega os recursos possíveis pelos meios eletrônicos. Muitas vezes, essa mídia serve apenas como meio para divulga- 
ção de poemas que podem perfeitamente ser veiculados pelo meio impresso, universalizando o acesso. Igualmente, as poesias digitais não aproveitam da mesma maneira os recursos disponíveis, sendo variáveis os modos de exploração dos elementos da expressão e a convocação para a participação do leitor, estabelecendo diferentes modos de interação e exigindo diversos níveis de competência do internauta. Entre um tipo e outro de texto (os que empregam ou não os recursos eletrônicos), constrói-se, de um lado, o efeito de sentido de acabamento, de fechamento (já que o enunciado está realizado completamente na tela, do ponto de vista da sua textualização) e, de outro, de incompletude, de abertura, de processamento e de dinamicidade, devido ao fato de realizar-se em camadas sucessivas ou num desenrolar que pressupõe uma decisão e uma escolha do enunciatário, envolvendo uma espera e um sobrevir. As formas de interpretar e de participar da constituição do sentido também se diferenciarão, como veremos, ao menos como efeito de sentido.

Tomando apenas os textos que empregam recursos que os meios eletrônicos tornaram possíveis, examinaremos, então, uma espécie de tipologia de modos de ler pressupostos aos textos que qualificam, consequentemente, os leitores de poesia na internet, observando tanto o grau do seu saber fazer em relação à navegação na internet e ao acesso aos recursos da expressão, com a exploração ou não de todas as suas possibilidades, quanto em relação aos modos possíveis de fruição dos textos, considerado o tratamento estético da expressão e do conteúdo nos poemas.

Para tratar desses problemas, tomaremos, como base teórica, algumas categorias da gramática tensiva de Zilberberg (2011), tais como intensidade e extensidade, fechamento e abertura, aceleração e desaceleração, que dão conta da aspectualização que explica o processo de leitura na internet. 
Para a observação dos estilos de navegação na internet e de leitura dos poemas digitais, inspiramo-nos na análise feita por Floch (1995, p. 19-47) sobre o comportamento dos viajantes do metrô e seus modos de circular e vivenciar o espaço, adaptando-a aos estilos de navegação previstos pelos poemas, no nível da enunciação pressuposta e do enunciado. Buscamos, também, nas análises de Fiorin (1999, p. 101-117) e de Barros (1999, p. 119-133) considerações importantes sobre a experiência estética, bases para analisar os leitores (e leituras) de poesias digitais.

\section{Competência modal do enunciatário e participação na poesia digital}

Para tratar do estatuto do enunciatário em poesias digitais, é preciso refletir sobre sua competencialização para ter acesso às camadas de enunciado, instauradas por gatilhos no enunciado, o modo de construção hipertextual nessas poesias eletrônicas. Não se pode deixar de considerar que a leitura e a interpretação de textos eletrônicos estão necessariamente atreladas a uma gestualidade, a determinadas decisões e escolhas, por meio de elementos inscritos no enunciado que apelam sensorialmente para a ação pragmática do leitor. Os diferentes modos de navegar esperados, sejam mais automáticos e contínuos, sejam mais exploradores e descontínuos, produzem seus efeitos e constituem verdadeiras estratégias, no sentido que lhe dá Fontanille (2008), reconstituíveis pela própria organização dos enunciados. Essas estratégias pressupõem um saber específico, que competencializa o leitor a alcançar outros estratos de enunciados realizados, a partir de suas escolhas e de suas ações. 
A competência do leitor envolve, então, um saber cognitivo, que implica um conhecimento sobre as formas de textualização dos enunciados desse tipo de poema, cuja constituição modal se baseia, de um lado, num poder fazer e num poder ser e, de outro, num dever fazer. É preciso que o leitor reconheça os links que lhe permitam ter acesso a outros estratos de enunciado realizado e, dentre os links inscritos, decidir e selecionar algumas trajetórias que se materializarão em uma sintaxe de enunciados que se encadearão de uma maneira particular, percebida como imprevista. É preciso ressaltar que essa imprevisibilidade só ocorre como efeito de sentido apreendido pelo leitor, já que todas as possibilidades combinatórias, mesmo inumeráveis, já estão dadas na organização discursiva e textual do enunciado. Assim, além de fazer reconhecer os gatilhos para os hipertextos, a fim de que o fazer interpretativo se realize, o enunciador precisa levar o leitor a um dever fazer - realizar ações de acesso a combinações sintagmáticas de enunciados a concretizar-se, pressupondo um corpo com certos graus de habilidade gestual específica.

Há, então, poemas cuja textualidade é dotada de elementos expressivos acessíveis a leitores modalizados por um grau mínimo de saber fazer relativo à navegação na internet. Há os poemas que exigem um pouco mais de habilidade gestual, uma vez que os recursos inscritos no enunciado ou possuem um menor grau de facilitação ou são acompanhados de instruções que conduzem à ação necessária do leitor. Enfim, existem poemas que supõem um ciberleitor, enunciatário dotado de um saber específico, capaz de reconhecer os gatilhos e modos de acesso aos links, de mover, arrastar elementos virtuais que produzem transformações e até de mover-se destramente por trajetórias virtuais, driblando obstáculos, para atingir objetivos imprevisíveis, imergindo no enuncia- 
do, por meio de procedimentos de embreagem ${ }^{2}$, interagindo como actantes do enunciado (como o exigido em alguns jogos eletrônicos mais sofisticados).

Portanto, os vários graus de habilidade dos leitores se inscrevem nos próprios enunciados, consideradas não só a natureza dos recursos empregados (inscrição de links, versos em movimento que devem ser clicados para dar continuidade ao poema, incursão no texto por mecanismos de embreagem etc.), dado o nível mínimo de competência de navegação e destreza gestual que permite o enunciatário manejá-los, mas também a presença ou a ausência de comandos verbais (ou verbovisuais ou até cinéticos) que dotem o enunciatário de um saber fazer que lhe possibilite experimentar as possibilidades expressivas do texto (clique aqui, mova o mouse etc.). As descrições dos procedimentos estéticos e técnicos, que antecedem a execução do poema, como página intermediária obrigatória, em muitos casos, também é um procedimento de regular e de doar saber ao enunciatário, circunscrevendo a abertura do poema e indicando um modo de atribuir-lhe sentido.

Para exemplificar essa graduação de saberes e habilidade gestual pressupostas pela variedade de poemas digitais publicados na internet, tomemos os poemas 450/Rio, de André Vallias ${ }^{3}$, Nem, de Arnaldo Antunes ${ }^{4}$, e Palavrador, de Chico

2 A embreagem, segundo Fiorin (1996, p. 84), “consiste na neutralização de oposições no interior da categoria de pessoa", nesse caso instituindo também a ilusão de uma quebra na hierarquia dos níveis de projeção enunciativa.

3 Disponível em: http://www.erratica.com.br/opus/127/index.html〉. Acesso em: 13 dez.2015.

4 Disponível em: 〈http://www.erratica.com.br/opus/3/index.html〉. Acesso em: 13 dez.2015. 
Marinho ${ }^{5}$.

0 poema de André Vallias se realiza aos olhos do leitor por meio de apenas um clicar inicial. Um processo acelerado de substituição vocabular tem então início, ocorrendo de modo que um segmento silábico final dos lexemas - RIO - fique estático e o segmento inicial se modifique com uma rapidez tão vertiginosa que não é possível percebê-lo. Para isso, o leitor deve apenas passar o sinalizador por sobre a palavra, para que se suspenda o movimento contínuo e veloz, visual e sonoro, e seja possível perceber o segmento inicial da unidade sígnica. Para o leitor, a apreensão da estrutura do plano da expressão e do plano do conteúdo é alcançável por meio de uma gestualidade simples, o clicar, pressuposta ao ato de ler na internet.

Imagem 1 - 450/Rio, de André Vallias

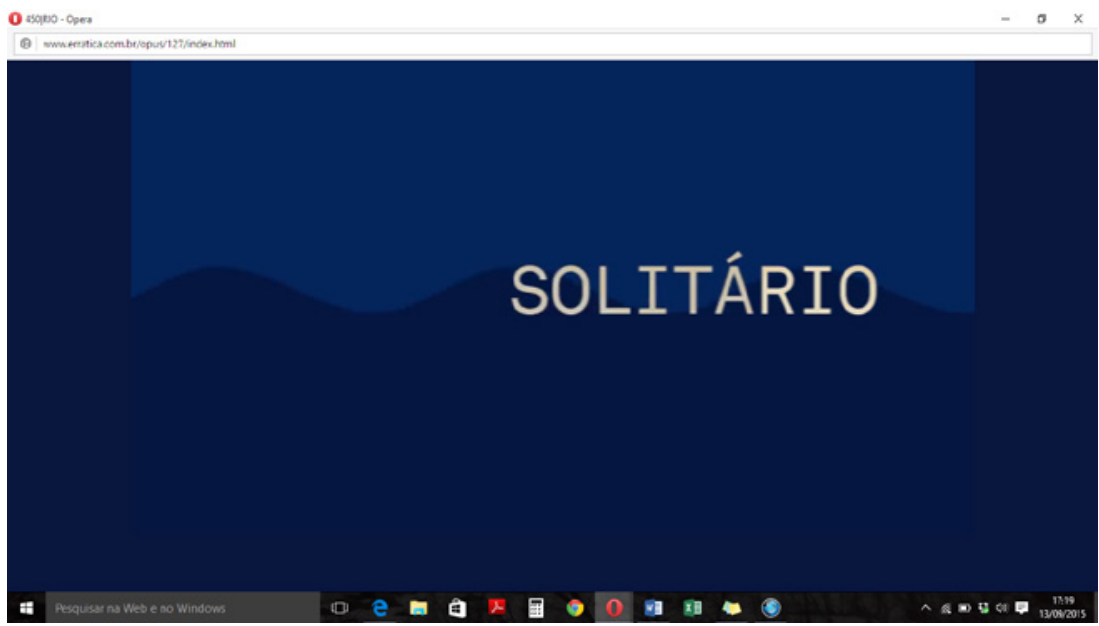

Fonte: Errática. Print da página.

5 Disponível em: 〈http://collection.eliterature.org/2/works/marinho_palavrador/palavrador.mp4>. Acesso em: 13 dez. 2015. 
Os mesmos movimentos gestuais (clicar e passar o sinalizador pelo acionamento do mouse) são obrigatórios para a concretização dos enunciados do poema Nem, de Arnaldo Antunes. Neste texto, após a realização do vídeo - sílabas que, distribuídas uniformemente por uma superfície quadrangular, são ressaltadas, em relevo, ao mesmo tempo em que uma voz diz outra sílaba não destacada do quadro -, há a possibilidade de arrastar o sinalizador por sobre o enunciado e dar continuidade ao desenvolvimento verbo-visual do texto, indefinidamente.

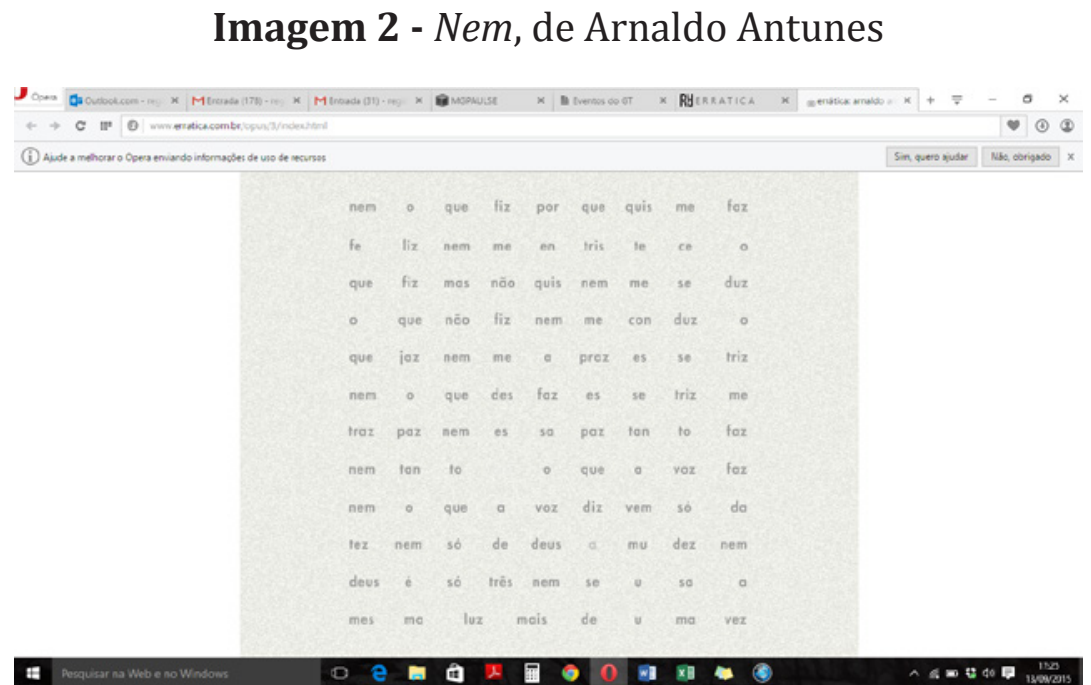

Fonte: Errática. Print da página.

Nesses dois casos, apesar de as ações pragmáticas presumidas serem bastante simples e fáceis, não há nada que indique a existência de gatilhos para que esses novos estratos de enunciados ocorram. Com os links ocultos, se o leitor não arriscar e não tiver curiosidade para experimentar, nada 
acontece. 0 próprio texto aponta, portanto, para o fato de que o seu destinatário, além de curioso e experimentador, saiba como funciona a textualização no texto digital, um conhecimento prévio pressuposto a uma forma de operar necessária para que o enunciado se realize em suas formas possíveis.

Há poemas ainda que supõem grande experiência para o manejo de mouse, teclados, para mover elementos virtuais num determinado ritmo e velocidade, para alcançar outros estágios do texto, que alguns internautas dificilmente atingirão. Um exemplo é o poema Palavrador, de Chico Marinho, que, como um jogo de videogame, o leitor deve manejar o teclado ou mouse para deslizar pelo espaço virtual em 3D e ir atingindo outros estágios do enunciado. Na publicação do vol. 1 do Electronic Literature Collection, o texto de introdução ao vídeo, que simula a construção do enunciado pela ação hábil do internauta, explica:

Palavrador é uma obra de autoria coletiva que nos oferece uma imagem de nós mesmos como uma mistura ou um equilíbrio estranho, de "eros" e "caos". Transferido para um mundo 3D, como uma espécie de animal voador, o usuário inicia uma viagem durante a qual navega poemas que são eles próprios tornados dinâmicos por algoritmos de IA. 0 processo de leitura aqui é processado como navegação intuitiva, o usuário batendo contra os "rebanhos" de palavras que vagueiam pelo ambiente de videogame. ${ }^{6}$

6 Texto original: "Palavrador is a work of collective authorship that offers us an image of ourselves as a mixture, or at least strange balance, of 'eros' and 'chaos'. Transferred into a 3D world as a kind of flying animal, the user starts a journey during which she navigates poems that are themselves made dynamic by AI algorithms. The reading process here is rendered as intuitive navigation, the user crashing against the "flocks" of words that themselves wander through the video game environment". Disponível em: 〈http:// collection.eliterature.org/2/works/marinho_palavrador/palavrador.mp4). Acesso em: 13 dez. 2015. 
Imagem 3 - Palavrador, de Chico Marinho

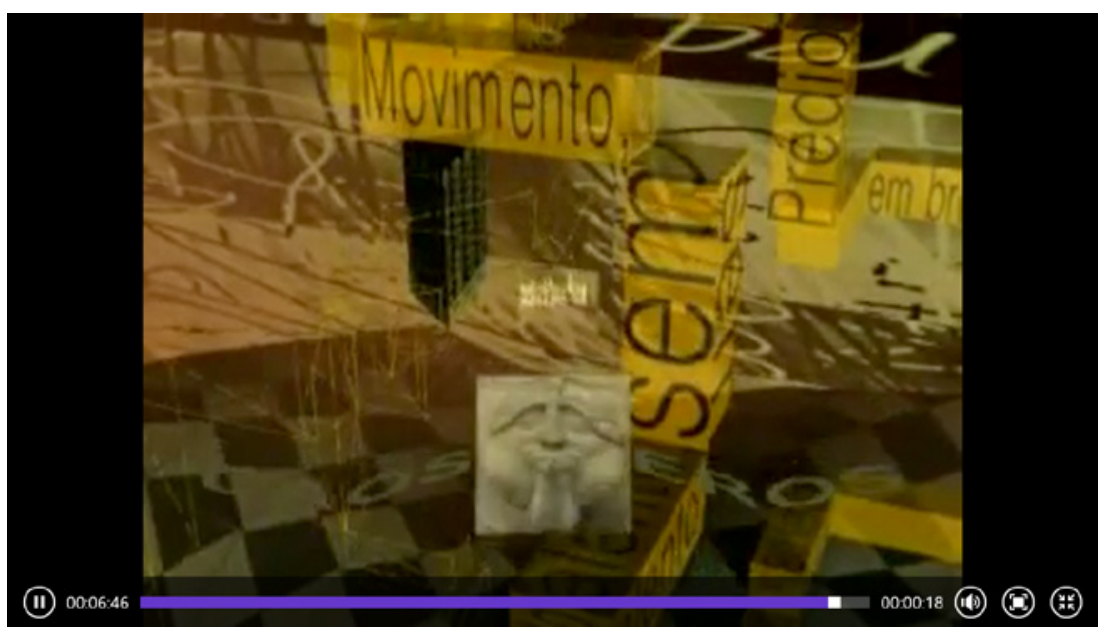

Fonte: Electronic Literature Collection, v. 1

As habilidades e modos de ação previstos nos diversos poemas da internet podem estar inscritos no enunciado por meio de instruções e comandos que tanto despertam a curiosidade do leitor e o convidam a manter-se em interação quanto são uma forma de o enunciador doar um saber fazer que dá ao enunciatário a competência para concretizar o enunciado e interpretá-lo.

Os comandos que orientam para as formas de interagir com o poema figurativizam como se lê na internet, em que o acesso ao enunciado e sua realização na tela envolvem o corpo do leitor e demandam ações. É o caso do poema Augusto, de Adriana Calcanhoto ${ }^{7}$, por exemplo, que instiga o leitor a usar o mouse para experimentar novas possibilidades combinatórias das palavras do poema.

7 Disponível em: 〈http://www.erratica.com.br/opus/104/adriana.html». Acesso em: 13 dez.2015. 
Imagem 4 - Augusto, de Adriana Calcanhoto

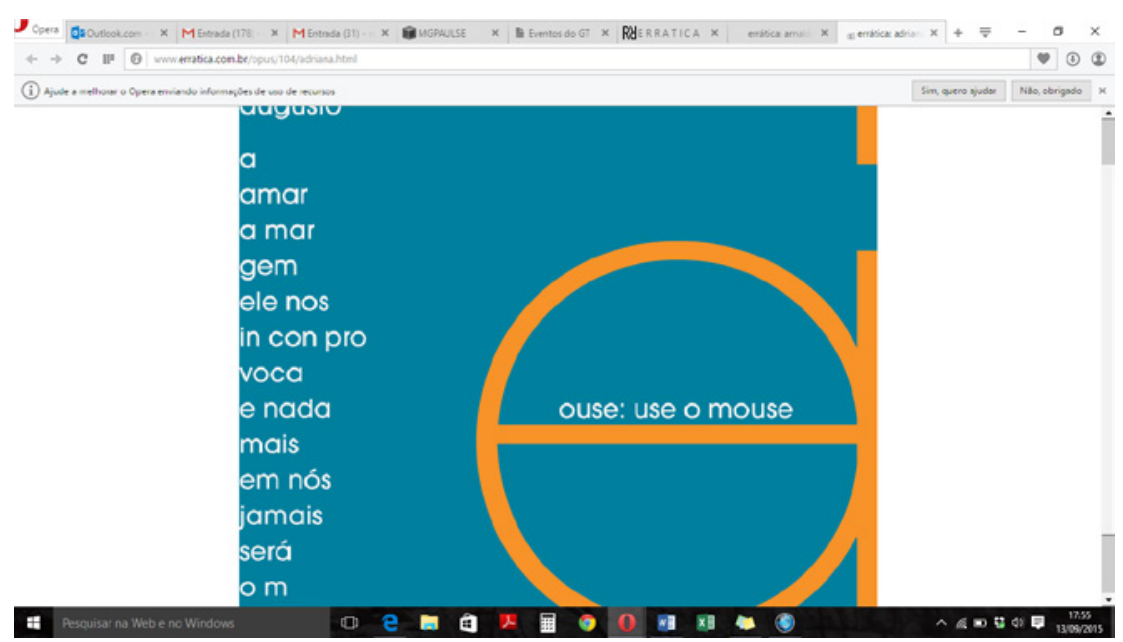

Fonte: Errática. Print da tela.

Nos textos que apresentam recursos mais complexos de expressão áudio-verbo-visual, há verdadeiras descrições dos processos utilizados e instruções de navegação. Podemos exemplificar com os textos Amor de Clarice $^{8}$ e Poemas no meio do caminho $^{9}$, de Rui Torres. Em ambos os poemas, páginas com instruções os antecedem, com explicações como "O leitor pode clicar e arrastar palavras para ouvir textos" ou "Em cada filme há um menu de navegação que lhe permite escolher navegar de modo linear ou aleatório". Inscreve, assim, leitores com menor habilidade de manejo com os comandos digitais.

8 Disponível em: 〈http://collection.eliterature.org/2/works/torres_amor_de_clarice/ amordeclarice/>. Acesso em: 13 dez. 2015.

9 Disponível em: 〈http://collection.eliterature.org/2/works/torres_poemas_no_meio/index.html >. Acesso em: 13 dez. 2015. 
Imagem 5 - Amor de Clarice, de Rui Torres

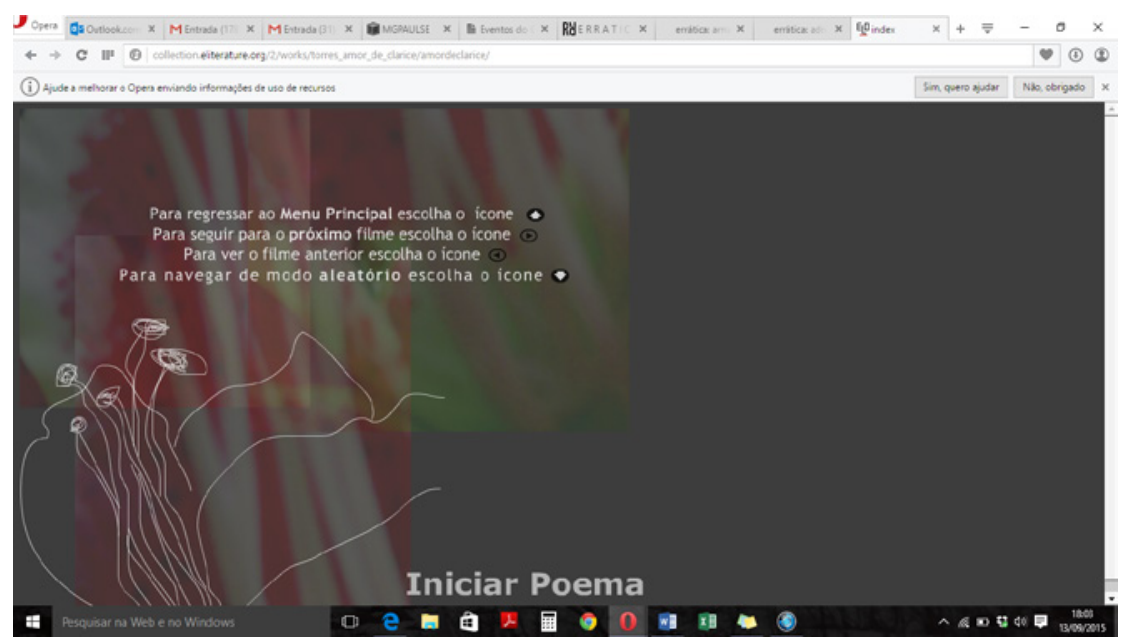

Fonte: Electronic Literature Collection, v. 1. Print da tela.

Imagem 6: Poemas no meio do caminho, de Rui Torres

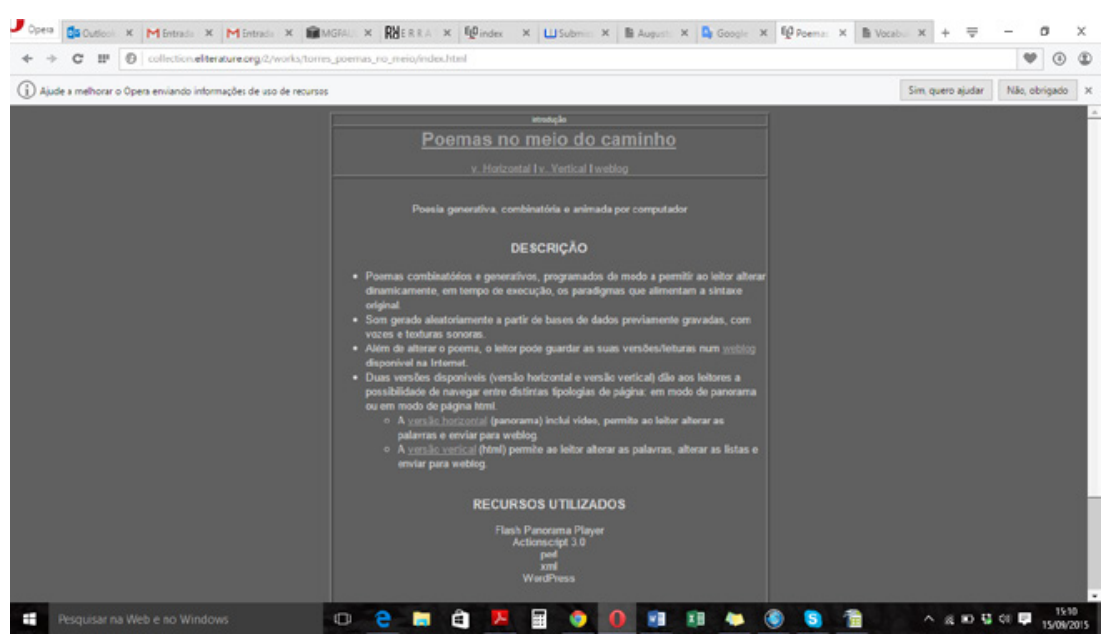

Fonte: Electronic Literature Collection, v. 1. Print da tela.

Ao mesmo tempo que apresenta a descrição das possibilidades combinatórias dos elementos expressivos e os con- 
sequentes estratos de enunciados possíveis, assim como os modos de perceber os recursos, concretiza metadiscursivamente o aspecto acidental da leitura, o que é ou não percebido pelo destinatário do texto para a construção global do sentido. Ao dizer, por exemplo, "ouse: use o mouse", o enunciador torna evidente a possibilidade de o leitor não descobrir algum elemento inscrito no texto e, em decorrência disso, não o considerar na interpretação, deixando no modo virtual algum plano de leitura. 0 poema que se realiza em camadas simula os diversos planos de significação da obra literária e põe em questão a telicidade e o fechamento do enunciado poético. Enfim, chama também a atenção ao processo como valor significante da obra.

A imperatividade das ações pragmáticas, além das tomadas de decisões do leitor e sua eleição de trajetórias de encadeamentos sintagmáticos na construção de camadas hipertextuais de enunciados, dentre as várias inscritas pelo enunciador, implica a participação somática, sensível e cognitiva do leitor, em diferentes graus, a ponto de criar a ilusão de que este é também autor do texto. Para além da inscrição do enunciatário como coprodutor do enunciado, discursivizado como imagem construída que orienta as escolhas do enunciador, considerada na própria noção de sujeito da enunciação, a interação enunciador-enunciatário cria a ilusão de autoria coletiva do texto. Mitigam-se, assim, os diferentes papéis do enunciador e do enunciatário na produção do enunciado.

A diversidade de poemas, com emprego diverso de recursos, traz gradações no que diz respeito a essa interação. Como vimos, tanto há poemas em que a participação do leitor se restringe a um clique quanto poemas que exigem uma imersão no texto, por meio do procedimento de embreagem, principalmente diluindo as fronteiras entre enunciação e 
enunciado e entre enunciador e enunciatário, produzindo sincretismos. Como exemplo de formas de interação mais intensas, no poema Palavrador, de Chico Marinho, acima citado, o leitor pode se mover no espaço figurativizado do enunciado por meio de uma espécie de avatar. Outra forma de participação está a interferência do leitor nos enunciados dos versos, a partir das suas escolhas entre elementos de um paradigma virtual, como ocorre em Poemas do meio do caminho, de Rui Torres, também já mencionado. 0 resultado dessas alterações pode ser enviado para um blog, constituindo um arquivo, onde cada verso surgido pela intervenção aleatória do leitor fica inscrito, sendo a ele atribuída autoria. No texto de introdução, percebe-se a confusão quanto à forma de tratar o enunciado advindo da ação do leitor:

\section{Introdução ao Poemário}

Neste blog estão arquivadas leituras de poesia combinatória usando o software Poemário, de Rui Torres (conceito) \& Nuno F. Ferreira (programação).

Poemário é uma aplicação programada em Actionscript 3.0 que permite a qualquer utilizador construir textos (poemas, narrativas, cartas, etc.) seguindo procedimentos combinatórios. Trata-se, até certo ponto, de uma atualização, ou recriação, do Sintex, de Pedro Barbosa, Abílio Cavalheiro e José M. Torres. As suas bases de configuração poética estão presentes / pendentes nos trabalhos experimentais de E. M. de Melo Castro e Herberto Helder.

Para criar seu próprio poema, siga o link para aplicação web (HELP brevemente disponível) (POEMÁRIO, grifo nosso $)^{10}$.

10 Disponível em: «ttp://telepoesis.net/poemario/?page_id=2〉. Acesso em: 13 dez. 2015. 
Ora considerados como "leituras de poesia combinatória”, ora como uma produção textual segundo processos combinatórios ("permite a qualquer utilizador construir textos [...] seguindo procedimentos combinatórios"), os enunciados publicados no blog concretizam o efeito de participação e de interação necessários para que a poesia se realize, novamente intensificado e explicitado.

A natureza complexa e heterogênea dos destinatários desses poemas digitais sincréticos, com saberes, com habilidades e com diferentes graus de interação previstos, pode mesmo se condensar em um só poema, como se pode constatar em Poemas no meio do caminho, de Rui Torres. Esse poema é emblemático nesse sentido, com suas duas versões (horizontal e vertical) e as diversas formas de participação do leitor em cada uma delas, exigindo diferentes graus de agilidade com os instrumentos dos meios eletrônicos e de intervenção do enunciatário. Na versão vertical, o leitor pode ler e ouvir os versos simplesmente, ou clicar nas palavras dos versos, fazendo surgir outras que a substituem, a partir de um paradigma. Mas é possível também alterar o paradigma, incluindo ou excluindo palavras, que podem substituir-se umas às outras, constituindo diferentes enunciados, cuja estrutura sintática mantém-se intacta. Na versão horizontal, a intervenção do leitor ocorre de outra forma. Uma alternativa é apenas assistir ao movimento do espaço, o fluir dos versos e ouvi-los pela voz do narrador. A interação mais ativa é a outra opção dada, exigindo maior destreza do enunciatário para rodar o panorama visual e mover-se pelo espaço, para cima, para baixo e para os lados, além de modificar lexemas de uma estrutura sintagmática fixa por meio de cliques, sem que, no entanto, seja possível alterar opções do paradigma.

Dotados de uma competência variável, os enunciatários 
apresentam estilos de navegar diferentes concernentes à variedade dos poemas digitais, com implicação nos modos de vivenciar os objetos estésicos e estéticos, como veremos a seguir.

\section{Estilos de leitura e apreciação estética}

Como vimos na seção anterior, há considerável variabilidade na configuração dos poemas digitais, apesar de explorarem todos o sincretismo de linguagens e recursos expressivos polissensoriais. Esses poemas, pelo emprego de recursos que exigem diferentes níveis de habilidade e conhecimento prévio sobre a textualização na internet, também inscrevem enunciatários que podem assumir diferentes estilos de navegação, leitura e envolvimento estésico-estético. Desse modo, há os poemas que se caracterizam por acentuar o caráter atélico, imperfectivo do texto literário, instalando links que permitem um número considerável de combinações sintagmáticas, constituindo várias camadas de enunciados, cuja totalidade não raras vezes é intangível. Esse é o caso do poema Amor de Clarice, já citado. Há outros que são marcados por sua natureza mais télica e perfectiva, como Fórmula do Mar, de Marcelo Tápia ${ }^{11}$ ou Poema-bomba de Augusto de Campos ${ }^{12}$, que, apesar de não deixar de dar ênfase ao processo, o faz em direção a um fim, de modo a produzir um fechamento, ao menos do ponto de vista de sua textualidade.

Essas formas de organização textual e de tratamento do plano da expressão são passíveis de serem explicadas pelas

11 Disponível em: 〈http://www.erratica.com.br/opus/80/formula.html». Acesso em: 13 dez. 2015.

12 Disponível em: 〈http://www2.uol.com.br/augustodecampos/bomba.htm〉. Acesso em: 13 dez.2015. 
categorias abstratas da continuidade e da descontinuidade, aspectualizando as trajetórias de leitura na internet. Esse modo de ler mais especializado nos faz recorrer, a título de inspiração, à análise de Floch (1995, p. 19-47) sobre os usuários de metrô, empregando essas mesmas categorias de base, apesar de o objeto de observação e os resultados encontrados não se aplicarem diretamente a nossa análise. No entanto, o trajeto pelo texto digital que o leitor cumpre também é marcado por limites, segmentações, etapas, que se ligam e se estruturam sob certas regras, como é o realizado pelo viajante do metrô. É caracterizado, ainda, por uma aspectualização específica, de acordo com as formas de textualização - iterativa, direcionada para um fim, multiorientada, acelerada ou desacelerada.

Os textos inscrevem seus leitores, ora disponíveis às exigências das descontinuidades - rendendo-se a percorrer os espaços virtuais ou diversos links, a aceder às sobreposições de enunciados, a tomar decisões entre opções de continuidade - ora expectadores, concentrados no fluxo contínuo do texto, de caráter imperfectivo ou não.

Ao empregar a estratégia mais descontínua (ou não contínua, já que se trata mais de segmentações que de demarcações), os textos impõem maior participação somática ao enunciatário, mas lhe permitem que por eles se mova numa temporalidade própria, com paradas, recuos e retomadas. Se os recursos empregados levam a um modo de ler descontínuo, os encadeamentos resultantes são múltiplos e contínuos, muitas vezes indefinidos.

As estratégias da continuidade obrigam o enunciatário a acompanhar os ritmos, a rapidez ou lentidão, a orientação dada pelos textos. Apesar de o enunciado ocorrer em fluxo contínuo, linear, sem intervenção do enunciatário após o clique inicial, muitos desses poemas são circunscritos em um só 
estrato, sem links que levem a outras páginas ou camadas de enunciados sobrepostos, instaurando um fechamento, uma descontinuidade, portanto. Ou seja, são demarcados espacialmente pelo enquadramento em uma só página ou temporalmente por um início e um fim em seu modo de textualização.

Essa complexidade caracteriza os textos na internet se, do ponto de vista do estilo de leitura, o ato é descontínuo, no que se refere ao encadeamento sintagmático do enunciado, há abertura e continuidade, e vice-versa.

Essas estratégias de leitura, decorrentes dos mecanismos expressivos do poema, produzem efeitos na construção do seu sentido, intensificando e concretizando a participação do leitor, o seu modo de vivenciar a experiência estética, a imersão no texto literário.

Prevendo uma intervenção mínima do enunciatário, o poema 450/Rio, de André Vallias, já mencionado, enfatiza a continuidade como estratégia expressiva. 0 poema recria o fluxo acelerado e ininterrupto do curso das águas do rio em oposição à margem, fazendo o leitor senti-lo visual e sonoramente. Não é possível discriminar, vocal ou graficamente, nenhum signo, e o sentido do texto se dá pelo próprio fluir veloz do texto. Ao passar o mouse sobre o fluxo dos vocábulos, é possível estancar o movimento e alguma palavra surge. Mas uma ou outra palavra solitária, aleatoriamente capturada, constituindo versos esparsos, não é suficiente para a apreensão da significação de enunciados coerentes, do ponto de vista inteligível. Ao mesmo tempo, a vocação metalinguística do poema se impõe: tanto fala sobre a rima, segmento vocal (ou gráfico) estável nas palavras, reiterado na urdidura sonora e visual do poema, quanto da sobreposição de estruturas paradigmáticas, tão recorrente na arquitetura expressiva da poesia. A fusão propiciada pela experiência estética (GREIMAS, 2002, p. 87) se dá pelo sentir, 
pela percepção imprimida por meio do simulacro de elementos do mundo recriados no texto, num dos planos de leitura, e pela intensificação e concretização acelerada e concentrada da expressão poética, no segundo plano de leitura.

Diferentemente, em Poemas no meio do caminho, de Rui Torres, na sua versão horizontal, toma a forma de um vídeo que permite ao leitor avançar sobre uma superfície em 3D, colhendo, no meio do caminho, os versos espalhados pelo espaço construído visualmente no poema. Simula-se, portanto, uma imersão do enunciatário no enunciado, pelo procedimento de embreagem actancial, como se ele seguisse uma trajetória no espaço tridimensional do enunciado. 0 enunciatário, então, perde-se no espaço do enunciado, movimenta-se e enxerga o panorama da posição que um actante do enunciado o faria. Os movimentos desajeitados e fugidios ou firmes e lineares simulam os de um corpo sensível, que explora os diferentes cenários enquanto avança pelo espaço.

Imagem 7 - Poemas no meio do caminho, de Rui Torres

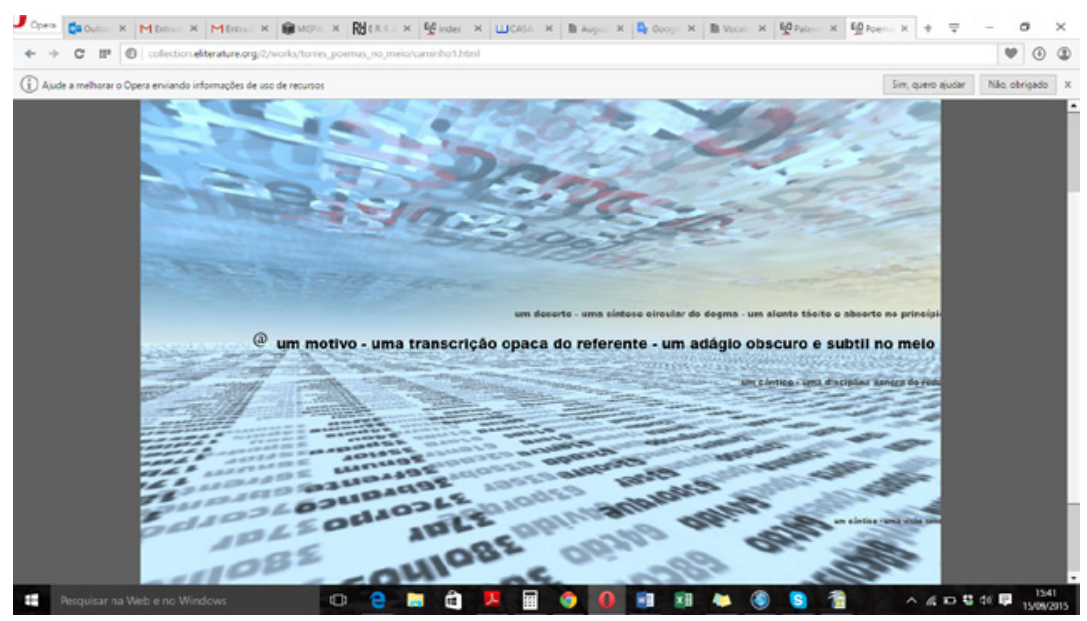

Fonte: Electronic Literature Collection, v. 1. Print da tela 
Os versos espalhados pelo espaço modificam-se continuamente, pela substituição de lexemas, e uma voz declama outros versos, que já não podem mais ser lidos. É como se o enunciatário estivesse em contínua busca dos versos e dos sentidos que lhe escapam. A fusão estésica do sujeito e do objeto se intensifica.

Como se vê, todas essas obras caracterizam-se por enfatizar "uma poética da expressão" (FIORIN, 1999, p. 113-117), em que o plano da expressão concentra o sentido do texto, intensificando os aspectos afetivos e sensoriais próprios do poético. Promovendo o sincretismo de linguagens, rompendo as fronteiras com as diversas artes, o poema digital intensifica a experiência sensível, iconiza os processos que nos meios impressos surgiam como efeitos de sentido (efeitos de profundidade visual ou sonora ou de movimento, por exemplo).

A elaboração estética do plano do conteúdo e do plano da expressão dos poemas, utilizando os mecanismos próprios da mídia eletrônica, supõe um leitor capaz de apreender esses vários recursos polissensoriais e experimentá-los. Um leitor que observa tanto os arranjos rítmicos, cromáticos, cinéticos, eidéticos, melódicos, enfim, os recursos audiovisuais, polissensoriais e seu tratamento expressivo, quanto as redes metafóricas e metonímicas, as formas de organização isotópicas de temas e figuras, os modos de projeção enunciativa, as transgressões criativas de níveis de enunciação, os efeitos de polifonia, as maneiras de compatibilizar e incompatibilizar conteúdos das diversas linguagens em sincretismo. 0 prazer de ler decorre das descobertas dos arranjos expressivos e da estruturação do conteúdo e da expressão. 


\section{Conclusões}

Os poemas digitais trazem para o analista novos problemas, que não estavam presentes nos poemas impressos do mesmo modo, relativos à sua abertura e ao modo de participação do enunciatário, questões que devem ser enfrentadas por surtirem certos efeitos na construção do sentido.

No que se refere à abertura do texto, sua totalidade é muitas vezes intangível, dada a multiplicidade de combinações sintagmáticas possíveis por meio das escolhas imprevistas do enunciatário. Sua interpretação, portanto, não pode abranger a globalidade do enunciado, não pode ter a pretensão de ser exaustiva, mas deve ser construída tomando em conta a incompletude e a instabilidade próprias desse tipo de poesia.

Relativamente à premência da participação do leitor, os textos, como são construídos, pressupõem um saber cognitivo e pragmático em diferentes graus, envolvendo um corpo sensível, capaz de acessar os vários links e imergir nos espaços virtuais por meio de uma gestualidade específica.

Essas ações previstas no enunciado pelo tratamento dado ao plano da expressão estão muitas vezes figurativizadas no enunciado, por meio de instruções de operação que competencializam o enunciatário a explorar os recursos expressivos instaurados pelo enunciador. É muito frequente que esses poemas estejam antecedidos de páginas explicativas, descrevendo as ações que devem ser realizadas pelo leitor para que os textos poéticos tenham plena existência. Apesar de não constituírem o texto poético propriamente dito, essas instruções ilustram os graus de habilidade técnica exigidos pelos recursos expressivos. Além disso, essas páginas descritivas são um passo necessário para alcançar o poema, o que acaba por imprimir no leitor uma determinada orientação de leitura. 
O enunciatário dos poemas digitais, portanto, não se configura de forma homogênea, seja do ponto de vista da sua competência e habilidade requeridas para o pleno acesso aos recursos, seja do ponto de vista da forma como interage com o texto e dele participa, seja do ponto de vista de seu estilo de leitura e fruição estética. Essa heterogeneidade se traduz e se condensa na própria constituição do enunciado - nas instruções dadas aos leitores, na convocação ao leitor para intervir no texto, nos diversos tratamentos estéticos da expressão. A obra Poemas no meio do caminho, de Rui Torres, é emblemática nesse sentido, já que reúne essa heterogeneidade de experimentação estésica e estética em suas duas versões (horizontal e vertical).

Enfim, pode-se questionar se esses modos de ler não são bem correspondentes aos de um texto não digital, da poesia que não lança mão dos recursos eletrônicos. A descontinuidade interposta pela hipertextualidade e pelas várias trajetórias decorrentes das possibilidades combinatórias próprias da poesia eletrônica está presente, de outra maneira, ao menos como efeito de sentido, na poesia impressa, especialmente na concreta. No entanto, a poesia digital amplifica as possíveis trajetórias de leitura, materializando, em enunciados concretos, as escolhas e encadeamentos de elementos isotópicos que instauram os planos de sentido, em progressão geométrica (já que os enunciados concretos instaurados pela navegação, por sua vez, permitem novo processo de leitura, que envolve descoberta, escolha e encadeamento, ou seja, outros planos de leitura sobrepõem-se). Na internet, acentua-se, portanto, o processo dinâmico da escritura, assim como as possibilidades imprevistas e, em alguma medida, acidentais (porque polissêmicas) de interpretação. 0 inacabamento do texto, seu caráter aberto e indefinido, se intensifica. 
A poesia digital, portanto, sem romper completamente com as formas mais convencionais de experimentação e fruição estética, põe em foco novas formas de elaboração expressiva, que, ao mesmo tempo que respondem a uma exigência de nossa época e muito diz do nosso modo de estar no mundo, aponta para a possível mudança das formas de vida.

\section{REFERÊNCIAS}

BARROS, D. L. P. de. "De la perfection": duas reflexões. In: LANDOWSKI, E.; DORRA, R.; OLIVEIRA, A. C. (EDs.). Semiótica, estesis, estética. São Paulo/Puebla: EDUC/UAP, 1999. p. 119-133.

ANTUNES, A. Nem. In: Errática. Disponível em: <http://www. erratica.com.br/opus/3/index.html>. Acesso em 13 dez. 2015.

CALCANHOTO, A. Augusto. In: Errática. Disponível em: <http://www.erratica.com.br/opus/104/adriana.html>. Acesso em 13 dez. 2015.

CAMPOS, A. Poema-bomba. In: Augusto de Campos site oficial. Disponível em: <http://www2.uol.com.br/ augustodecampos/bomba.htm>. Acesso em 13 dez. 2015.

FIORIN, J. L. As astúcias da enunciação: as categorias de pessoa, espaço e tempo. São Paulo: Ática, 1996.

FIORIN, J. L. Objeto artístico e experiência estética. In: LANDOWSKI, E.; DORRA, R.; OLIVEIRA, A. C. (EDs.). Semiótica, estesis, estética. São Paulo/Puebla: EDUC/UAP, 1999. p. 101117 
FLOCH, J.-M. Sémiotique, marketing et communication. Sous les signes, les estratégies. Paris: PUF, 1995.

FONTANILLE, J. Pratiques sémiotiques. Paris: PUF, 2008.

GREIMAS, A. J. Da imperfeição. Trad. Ana Claudia de Oliveira. São Paulo: Hacker Editores, 2002.

MARINHO, C. Palavrador. In: Electronic Literature Collection, v.2, 2011. Disponível em: <http://collection.eliterature. org/2/works/marinho_palavrador/palavrador.mp4>. Acesso em: 13 dez. 2015.

POEMARIO. Disponível em: <http://telepoesis.net/ poemario/?cat=5>. Acesso em 13 dez. 2015.

TÁPIA, M. Fórmula do mar. In: Errática. Disponível em: <http://www.erratica.com.br/opus/80/formula.html>. Acesso em: 13 dez. 2015.

TORRES, R. Amor de Clarice. In: Electronic Literature Collection, v. 2, 2011. Disponível em: <http://collection. eliterature.org/2 / works / torres_amor_de_clarice / amordeclarice/>. Acesso em: 13 dez. 2015.

TORRES, R. Poemas no meio do caminho. In: Electronic Literature Collection, v. 2, 2011. Disponível em: <http:// collection.eliterature.org/2/works/torres_poemas_no_meio/ index.html>. Acesso em: 13 dez. 2015. 
VALLIAS, A. 450/Rio. In: Errática. Disponível em: <http:// www.erratica.com.br/opus/127/index.html>. Acesso em: 13 dez. 2015.

ZILBERBERG, C. Elementos de semiótica tensiva. Trad. Ivã Carlos Lopes; Luiz Tatit e Waldir Beividas. São Paulo: Ateliê Editorial, 2011.

Artigo recebido em setembro de 2015 e aprovado em dezembro de 2015.

Disponível em: http://seer.fclar.unesp.br/casa 